\title{
O BRINCAR NO DESENVOLVIMENTO LÚDICO DA CRIANÇA
}

\author{
Renivaldo Santos de Souza ${ }^{1,}$ Odair Benedito Francisco ${ }^{2}$ \\ ${ }^{1}$ Faculdades EST, Mestrado em Teologia, São Leopoldo, RS. ${ }^{2}$ Universidade do Oeste Paulista - UNOESTE, Tutor em \\ Cursos de Pós-Graduação Lato Sensu EaD, Presidente Prudente, SP. E-mail: rennysousa@hotmail.com
}

\section{RESUMO}

Na concepção da aprendizagem como forma de interação social, sabemos da necessidade do trabalho com propostas da ludicidade no contexto infantil de forma contextualizada, considerando os requisitos necessários para um bom planejamento e formação dos professores nesta etapa. 0 objetivo deste trabalho foi demonstrar que no brincar a criança desenvolve a capacidade criativa, inteligência e habilidades de criação e atenção que serão relevantes em toda a sua vida. Foi utilizada como metodologia a abordagem qualitativa, do tipo de ensaio teórico, destacando a aprendizagem da criança e o contexto escolar, de forma global com ênfase na ação da ludicidade no currículo escolar e no projeto político pedagógico, refletindo sobre os aspectos favorecedores ou prejudicadores da aprendizagem da criança na educação infantil. Portanto, a prática do brincar contribuirá no contexto escolar para aprendizagem da criança numa perspectiva pedagógica envolvente e criativa em que a criança poderá aprimorar seus conhecimentos.

Palavras-Chave: Brincar, Criança, Aprendizagem.

\section{THE PLAY DEVELOPMENT LUDIC CHILD}

\begin{abstract}
In view of learning as a form of social interaction, we know the need of working with playfulness of the proposals in the child context in context, considering the requirements for good planning and training of teachers at this stage. The aim of this study was to demonstrate that the play the child develops creativity, intelligence and creation skills and attention that will be relevant throughout your life. It was used as methodology the qualitative approach, the type of theoretical essay, highlighting the child's learning and the school environment, globally with emphasis on the action of playfulness in the school curriculum and pedagogical political project, reflecting on favoring aspects or harm of child's learning in early childhood education. Therefore, the practice of playing in the school context contribute to the child's learning in a pedagogical perspective and creative environment in which children can improve their knowledge.
\end{abstract}

Keywords: Play, Child, Learning. 


\section{INTRODUÇÃO}

[...] Os homens são seres da práxis. São seres do que fazer... Se os homens são seres do que fazer é exatamente porque seu fazer é ação e reflexão. É práxis. É transformação do mundo. E, na razão mesma em que o que fazer é práxis, todo fazer do que fazer tem que ter uma teoria que necessariamente o ilumine. O que fazer é teoria e prática. É reflexão e ação [...] (FREIRE, 2001, p.121).

O brincar, como parte do nosso cotidiano, constitui-se uma tarefa maravilhosa, espontânea, interativa, integrativa e muito prazerosa, havendo o envolvimento do ser humano em todo tempo, desde os primeiros dias de vida até o fim dela. Isto porque, com o brincar, a criança solta sua imaginação, estimula sua capacidade, torna-se mais espontânea, enfrenta os desafios com mais facilidade, desenvolve a capacidade de mudar e aceitar novas regras, tornando-a mais curiosa, energética e autoconfiante.

Nesse sentido, o brincar é algo presente em várias civilizações antigas como instrumento de aprendizagem. É interessante destacar nessa perspectiva o fato de brincar estar sempre presente na história da humanidade e acessível a todo ser humano, contribuindo fundamentalmente para o seu desenvolvimento em todas as fases e estágios cognitivos e emocionais, pois, ainda para Wajskop (2001), os sábios greco-romanos utilizavam-se de dados, aritmética, isto é, jogos didáticos que determinavam a importância da educação sensorial. 0 autor ainda aponta que é fundamental uma transformação de concepção sobre o desenvolvimento da criança por meio de mudanças de paradigmas de todos os envolvidos no processo educacional.

Sob esta ótica, no momento, é preciso uma ruptura com pensamento romântico e assumir uma nova prática pedagógica que valorize a brincadeira, dando-lhe espaço de destaque na educação das crianças pequenas. Antigamente, a brincadeira era considerada ociosidade, vista por muitos como uma fuga, e a imagem social da infância não permitia e nem aceitava um comportamento infantil que pudesse significar algum valor em si (WAJSKOP, 2001, p. 12).

Vários autores contribuíram para essa nova postura de entendimento sobre o brincar na sua dimensão cognitiva e sua importância para o desenvolvimento da criança integrado para a sua educação, dentre eles Farias (2012), Almeida (2009) e Friedmann (2006), que surgiram nesse novo cenário científico-educacional como o "alvorecer da infância" para avaliar as crianças e como colaborar para que elas possam conquistar um espaço de aprendizagem (WAJSKOP, 2001, p. 20).

Entretanto, torna-se fundamental o envolvimento dos educadores e das crianças, com a valorização, a proteção e o respeito dispensados nessa nova concepção idealista e protetora da infância. Conforme Wajskop (2001) é preciso valorizar as verdadeiras propostas educativas que dão sentidos ao brincar para o desenvolvimento da criança com uma finalidade e objetivos definidos e claros, ou seja, toda prática pedagógica precisa estar ordenada de planejamento, com objetivos, metas, resultados esperados, fazendo usos pedagógicos dos brinquedos e centrada no divertimento, evidenciando assim o papel do educador de se preocupar com a qualidade de vida e do ensino. Nosso objetivo é demonstrar que por meio do brincar a criança pode desenvolver a habilidade de criação é a capacidade criativa, intelectual, critica e reflexiva.

\section{METODOLOGIA}

Nesse contexto contemporâneo, inicialmente observamos que em muitas escolas de Ensino Infantil que a brincadeira em estado ausente na vivência da criança, prejudicando o seu desenvolvimento e amadurecimento cognitivo. Portanto, partimos de uma análise de textos científicos publicados nas mais diversas fontes de pesquisa, tais como Scielo, Google Acadêmico, numa abordagem qualitativa, do tipo ensaio teórico, como método de investigação.

Segundo Meneghetti (2011), 
O ensaio é um meio de análise e elucubrações em relação ao objeto, independentemente de sua natureza ou característica. A forma ensaística é a forma como são incubados novos conhecimentos, até mesmo científicos ou pré-científicos. Não é instrumento da identidade entre sujeito e objeto, mas é meio para apreender a realidade, por renúncia ao princípio da identidade. Assim, surge como tentativa permanente de resolver a questão central da filosofia moderna: a separação e tensão permanente entre sujeito e objeto na compreensão da realidade (MENEGHETTI, 2012, p. 323).

Numa perspectiva qualitativa, buscamos evidências de que o brincar constitui-se um aspecto relevante como um instrumento didático-pedagógico no processo de ensino e aprendizagem. Cruz (2011, p. 21) afirma que "[...] ela trabalha com descrições, comparações, interpretações e atribuição de significados possibilitando investigar valores, crenças, hábitos, atitudes e opiniões de indivíduos ou grupos". Buscar-se-á formar com o brincar o imaginário das crianças, fazendo com que obtenham os conhecimentos necessários e adicionais para a aprendizagem. Nesse ponto, o ensaio teórico será essencialmente qualitativo, usando-se, por conseguinte, publicações e pesquisas para obter algumas inferências.

\section{ANÁLISE DOS RESULTADOS}

No cotidiano das instituições de educação infantil, o brincar é parceiro inseparável do educador. Nessa análise, sabe-se que o educador infantil precisa buscar sua formação inicial e continuada para construir nas creches e nas escolas infantis uma proposta que envolva a ludicidade com atividades concretas para despertar o interesse, a participação, o envolvimento das crianças com os brinquedos, independentes que sejam fabricados ou de sucatas, pois as contribuições para aprendizagem independem desse aspecto. "Brinquedos caros e professores despreparados constitui-se equação que agridem os fundamentos da aprendizagem e atiram pela escada abaixo todos os estudos e todos os progressos da arte de brincar e o desafio do aprender" (ANTUNES, 2011, p. 32).

Com efeito, cabe ao educador infantil, nas instituições de ensino infantil, construir metodologias com recursos adquiridos ou produzidos para promover e facilitar o ensino e a aprendizagem. É preciso compreender o papel fundamental do educador infantil no estabelecimento e enriquecimento do brincar como uma atividade que envolve todo o universo infantil. Concordamos com Maluf (2012, p. 29), ao afirmar que as atividades lúdicas têm que ocupar ou ter um espaço de destaque na educação infantil, nesse sentido "o lúdico é o parceiro do professor".

No entanto, o educador infantil cria verdadeiras estórias, constrói, oferece materiais adequados como jogos, atividades lúdicas, expressão corporal e movimentos, sugerem várias brincadeiras infantis e participa da imaginação lúdica da criança. Por isso, à medida que a criança vai interagindo com o mundo, os objetos e as outras crianças, há o estabelecimento de relações positivas e conhecimentos sobre o mundo em que vive. Nessas relações surgem oportunidades para o descobrimento de coisas interessantes, impressionantes e indispensáveis nesse processo de novas descobertas. Mello (2003, p. 30) destaca que as crianças conseguem expressar "suas fantasias, seus sentimentos, suas ansiedades e suas experiências" por meio das brincadeiras, 0 que favorece a construção da identidade pessoal e do conhecimento.

Por outro lado, os educadores e a família deverão promover uma ação que promova um pensamento de liberdade para a criança e que nesta situação de fato a socialização aconteça naturalmente com seus colegas, professores e demais pessoas. "Para que isso aconteça, a criança não deve sentir-se bloqueada, nem oprimida em seus sentimentos, sonhos e desejos. Suas 
diferenças e experiências individuais devem, principalmente na escola, ter um espaço relevante, sendo respeitadas nas relações com o adulto e com outras crianças" (MALUF, 2012, p. 31).

Esta declaração indica subliminarmente que deve existir uma relação entre a brincadeira e o desenvolvimento da criança, assim pode-se permitir que se conheça com mais clareza importantes nas funções mentais, como o desenvolvimento do raciocínio, da linguagem, da participação, por isso quanto mais à criança participa de brincadeiras, atividades lúdicas, surgem novas buscas de conhecimento e aprendizagens concretizadas de forma prazerosa, envolvente que começa na brincadeira a aprendizagem para uma nova concepção da educação contemporaneamente, ou seja, "brincando a criança desenvolve a imaginação, fundamenta afetos, explora habilidades e, na medida em que assume múltiplos papéis, fecunda competências cognitivas e interativas" (ANTUNES, 2011, p. 31).

Nessa perspectiva, a brincadeira, "como atividade separada e independente da criança que brinca", por estar intimamente relacionada com a ação de brincar que seria "uma experiência num continuum espaço-tempo, uma forma básica de viver" (Rosa, 2002, p. 40), exige uma organização planejada para ser considerada como uma atividade que promove recreação, divertimento, podendo utilizar-se do brinquedo como suporte para a sua realização.

Oliveira (2007, p. 231) afirma que a "brincadeira infantil beneficia-se de suportes externos para sua realização: rituais interativos, objetos e brinquedos". Assim sendo, podemos dizer que o brinquedo é fundamental para a brincadeira, por ser um objeto que lhe dá suporte e a orienta, com atributos lúdicos, utilizado como recurso de ensino ou material pedagógico (KISHIMOTO, 1998).

Nesse aspecto, podemos concordar com Vygotsky (2000) quando afirma que a brincadeira é decisiva no desenvolvimento da criança porque tem a grande possibilidade de libertá-la de situações-problema e difíceis. Justamente no brincar que as coisas e as ações não são o que aparentam ser; e, em situações imaginárias, a criança começa a explorar todo seu potencial e agir independentemente do que ela vê ou interage, orientando-se pelo significado da situação, dando sentido real aos símbolos a ela apresentados.

Para Vygotsky (2000), no desenvolvimento da criança é fundamental a compreensão de que ela tem a necessidade de ser incentivada, motivada, encorajada na realização das atividades lúdicas, que são características importantes na utilização do seu imaginário para descobrir as ações que se originam mais em ideias do que nas coisas. Então a criança usa a sua estrutura cognitiva para transformar a realidade e compreender melhor o mundo exterior.

Nesse sentido, a brincadeira desenvolve na criança um sentimento de liberdade por meio das atividades lúdicas, um sentimento de ações que precisam ser completadas, não pela ação em si mesma, mas pelo simbolismo ou significado que ela carrega de transformar a imaginação em algo real e concreto cheio de significado criativo e construtivo para a liberdade. "Esse processo dá à criança uma 'nova forma de desejos'. Além do nível do comportamento diário, habitual na sua idade, a atividade lúdica é o nível mais alto do desenvolvimento na infância, e é por ela que a criança se move cedo" (FRIEDMANN, 2006, p. 21). A partir dele, podemos avaliar o processo de desenvolvimento até o presente momento e os processos de maturação produzidos pela criança. Isso acontece para que a criança desenvolva novos relacionamentos durante o brincar entre significados e o sentido dos objetos e as ações.

Enfim, nesse momento ocorrerá na criança uma grande estimulação da criatividade, constituindo-se um grande processo de intenção educativa. É certo que, ainda há grandes questionamentos acerca da utilização desse recurso em sala. Os brinquedos são objetos que visam desenvolver o aspecto fundamental para o desenvolvimento integral da criança, possibilitando avaliar o processo de desenvolvimento de maturação da criança. 


\section{DISCUSSÃO}

Esta pesquisa demonstra que a brincadeira bem planejada e conduzida pelo educador infantil pode influenciar a imaginação da criança, promovendo uma grande estimulação da criatividade e da fantasia, constituindo-se um processo de intenção educativa, que libertará a criança "do estado de curiosidade ingênua para o de curiosidade epistemológica" (FREIRE, 1998, p. 43-44), possibilitando a aprendizagem. Na contemporaneidade, é impossível conceber a educação infantil que queria ser apenas como intermediadora de informações, ou seja, ela precisa se estabelecer como um espaço de construção coletiva para a difusão do conhecimento transformador, em que todos possam se envolver no processo de aprendizagem. "Todo aprendizado que o brincar permite é fundamental para a formação da criança, em todas as etapas da sua vida" (MALUF, 2012 p. 21). O brincar promove uma ação extraordinária no pensamento da criança, ajudando-a no desenvolvimento cognitivo, que são essenciais para a aprendizagem.

Destarte, precisamos valorizar as brincadeiras na educação infantil, atrelados à construção de aprendizagem significativa e, sobretudo, na tomada valores e a excelência do trabalho do educador, produzindo na criança uma autêntica transformação de conhecimento por meio de atividades recreativas e lúdicas (ANTUNES, 2011; MALUF, 2012).

A análise e resultados propostos consideram também que na educação infantil, o educador precisa estar atento para cada momento do brincar e realizar as devidas intervenções, uma vez que, o brincar não é apenas uma atividade recreativa e sim uma forma prazerosa de aprender, porque através dele a criança consolida o envolvimento e o desenvolvimento da aprendizagem.

Para isso, os educadores, precisam pensar na reelaboração das propostas didáticopedagógicas, especialmente quando essas são divididas em etapas de construção. Após este processo, acontece o brincar, produto final da produção do conhecimento para compreender os aspectos que envolvem o desenvolvimento da criança, quando Piaget (1971 apud Friedman, 2006, p. 21) nos fala sobre "os estágios do desenvolvimento da criança e a formação do símbolo na criança".

Portanto, esses conhecimentos qualificam os educadores, toda a equipe escolar, os demais profissionais para atender às necessidades contemporâneas que cada vez mais exigem da instituição escolar a capacidade de articulação do ensino com o mundo globalizado e as competências, as habilidades de saber utilizar as brincadeiras pedagogicamente para promover a aprendizagem, na lateralidade, na psicomotricidade, nos movimentos, motoras (FRIEDMANN, 2006).

\section{CONSIDERAÇÕES FINAIS}

Considerando a necessidade de melhoria do processo de ensino e aprendizagem na educação infantil, com modalidades que proporcionam constantes transformações, faz-se necessário em nossa sociedade como um todo, principalmente ao educador, oportunidades de formação permanente, que permitam práticas coerentes com os princípios que visam à transformação do sistema educativo infantil e também os desafios que dela decorrem. Na análise desse processo que permite, também, ao educador refletir sobre as implicações pedagógicas da ludicidade integrada ao currículo escolar da educação infantil e ao Projeto Político-Pedagógico, torna-se imprescindível a constituição de espaços de trocas de experiências, vivências lúdicas, busca e diálogo, nos quais também se manifestam as ligações entre a cultura escolar e o mundo da imaginação e da fantasia, do vivido no cotidiano da criança na escola ou fora dele principalmente como o brincar.

O brincar é uma realidade vivida pela criança em seu cotidiano, "quando a criança brinca ela está vivenciando momentos alegres, prazerosos, além de está desenvolvendo habilidades" (MALUF, 2012, p. 21). Através da imaginação a criança relaciona seus interesses e necessidades 
com a realidade de um mundo no qual vive. Uma educação identificada com a nossa realidade social, deve ser uma preocupação constante para o avanço das crianças.

Dessa forma, é papel da escola e dos pais discutirem, analisarem e refletirem sobre as práticas atuais de ensino, para que se perceba, afinal, que o conhecimento é algo construído por meio de trocas sociais, na vivência entre os seres humanos. A criança desde a infância traz para o espaço escolar toda uma experiência educacional adquirida durante o seu desenvolvimento na família e sua história. Os vários vínculos estabelecidos com a criança desde o nascimento influenciam na constituição da personalidade e determinam as condições necessárias para a aprendizagem. Nesse sentido, no ambiente escolar, o educador precisa conhecer a criança e o que ela traz para estabelecer uma relação de confiança em um ambiente acolhedor e lúdico.

Enfim, neste trabalho, buscou-se constatar a importância do brincar na infância e como ele contribui diretamente para a autoestima e desenvolvimento lúdico da criança, colaborando para a superação das dificuldades de aprendizagem e destacando que o educador deve compreender a criança e suas limitações para fortalecer o vínculo entre ambos. Neste contexto, a escola precisa elaborar um programa educacional eficaz para que transforme a sua realidade em um espaço de aprendizagem. A educação deverá ser pensada e planejada a partir da visão inovadora pedagógica e da dimensão da criança como pessoa que cria, inova e constrói. Assim, contribuirá para a formação na infância da criança, para que se torne cada vez um "ser mais" (FREIRE, 1998, p. 32).

\section{REFERÊNCIAS}

ANTUNES, C. Educação Infantil: prioridade imprescindível. Petrópolis, RJ: Vozes, 2011.

CRUZ, V. A. G. Pesquisa em educação: pedagogia. São Paulo: Pearson Prentice Hall, 2011.

FREIRE, P. Pedagogia da autonomia: saberes necessários à prática educativa. 8. ed. Rio de Janeiro : Paz e Terra, 1998. (Coleção Leitura). . Pedagogia do Oprimido. 30. ed. Rio de Janeiro: Paz e Terra, 2001.

FRIEDMANN, A. O brincar no cotidiano da criança. São Paulo, SP: Moderna, 2006.

KISHIMOTO, T. M. O jogo e a educação infantil. São Paulo: Pioneira, 1998.

MALUF, A. C. M. Brincar: prazer e aprendizado. 8. ed. Petrópolis, RJ: Vozes, 2012.

MELLO, M. M. O lúdico e o Processo de Humanização. In: MARCELLINO, N. C. (org.). Lúdico, educação e educação física. 2. ed. Ijuí: Ed. Unijui, 2003.

MENEGHETTI, F. K. Documentos e Debates: O que é um Ensaio-Teórico. In: RAC, Curitiba, v. 15, n. 2, p. 320-332, mar./abr., 2011.

OLIVEIRA, Z. R. Educação Infantil: fundamentos e métodos. 3. Ed. São Paulo: Cortez, 2007.

ROSA, S. S. Brincar, Conhecer, Ensinar. 3 ed., São Paulo: Editora Cortez, 2002.

VYGOTSKY, L. S. A formação social da mente: o desenvolvimento dos processos psicológicos superiores. 6. ed. São Paulo : Martins Fontes, 2000.

WAJSKOP, G. Brincar na pré-escola. São Paulo: Cortez, 2001. 